\title{
Recurrent Meningioma of the Cervical Spine, Successfully Treated with Liposomal Doxorubicin
}

\author{
William L. Read Felicia Williams \\ Winship Cancer Institute, Emory University, Atlanta, GA, USA
}

\section{Keywords}

Brain neoplasm · Liposomal doxorubicin · Meningioma $\cdot$ Chemotherapy

\begin{abstract}
There is no standard systemic treatment for persons with recurrent meningioma who have exhausted surgery and radiation options. Liposomal doxorubicin is a cytotoxic chemotherapy which is sustainable and tolerable, with activity against a range of solid tumors. There exists one reported case of metastatic meningioma effectively treated with liposomal doxorubicin. We report a second case. Our patient, a 35-year-old man with recurrent meningioma compressing the cervical spinal cord received liposomal doxorubicin for 22 months with clinical improvement, minimal toxicity, and slow regression of his tumor. He is well and without progression 18 months after stopping chemotherapy and 4 years after his last progression event.

(C) 2017 The Author(s)

Published by S. Karger AG, Basel
\end{abstract}

\section{Introduction}

Skull base meningiomas are difficult to treat. In the series reported by Mathiesen et al. [1], the majority of persons treated with subtotal resection went on to develop symptomatic recurrences, and $60 \%$ of these ultimately died of their disease. In persons who have exhausted options for surgery and radiation, there exists no standard systemic therapy. Al- 


\section{Case Reports in Oncology}

though there has been some enthusiasm in recent years for therapies targeting the vegF axis $[2,3]$, conventional cytotoxic or hormonal therapy is considered ineffective [4].

There is a single case report describing the successful use of liposomal doxorubicin in the treatment of a woman with metastatic meningioma [5]. We chose this treatment for our patient, a 35-year-old man with a skull base meningioma multiply recurrent despite serial surgeries and radiation. We are pleased here to report his excellent clinical outcome and long-term disease control.

\section{Case}

A 35-year-old man initially presented in February 2008 with nausea, vomiting, and weight loss. He was found to have a meningioma in his posterior fossa, compressing his cerebellum. He underwent resection and within a month, a second resection for residual tumor. He was then followed with serial imaging and in early 2009 underwent a third surgery for progressive tumor, this time followed by fractionated radiation.

He then did well until January 2013 when he suffered neck pain and the rapid onset of right-sided arm and leg weakness. Imaging found him to have a 1.4-cm enhancing mass at the cervicomedullary junction compressing his cervical spinal cord (Fig. 1a). Resection of this mass was complicated by subacute hydrocephalus necessitating the placement of a ventriculoperitoneal shunt 3 weeks later. Pathology on the resected mass described its similarity to rhabdoid meningioma, although with a low mitotic rate and without cellular atypia; the pathologists noted that although it did not meet histologic criteria for grade II, "the clinical history of this lesion suggests aggressiveness commensurate with at least WHO grade II."

One-week postop imaging showed that the enhancing mass was smaller but there was concerning residual disease (Fig. 1b). By March 25, 2013 the mass had clearly grown (Fig. $1 c)$, with increased pressure on the cervical spinal cord. At that time, he remained wheelchair bound and hemiplegic, although he felt no worse than at the time of his hospital discharge 2 months prior. Because he was thought to have exhausted surgery and radiation options, he was referred to us for consideration of systemic treatment. He began liposomal doxorubicin at $30 \mathrm{mg} / \mathrm{m}^{2}$ every 3 weeks, and he was tapered off his dexamethasone and started on testosterone replacement.

Two months later, repeat MRI showed no change in the mass representing his tumor. By 4 months, he could walk using a leg brace and could climb stairs. At cycle 6 (18 weeks), his interval was stretched out from every 3 to every 4 weeks. He continued on monthly liposomal doxorubicin for a total of 26 cycles over 22 months. His toxicity was limited to grade 1 hyperpigmentation of the palms. He received his last chemotherapy in November 2015 and we have continued to follow with surveillance imaging. At the time of this report (May 2017), he is well and can walk with a cane and drive, 4 years from his last progression event. Although serial MRIs have all called stable disease at the tumor of his cervicomedullary junction, the tumor there has actually slowly regressed over the years (Fig. 1d).

\section{Discussion}

We report our case in hopes that it might be helpful to clinicians and patients in the same way that the report by Travitsky et al. [5] helped us and our patient. We were pleased and surprised by his excellent outcome. Despite nearly 2 years of treatment, the low doses 


\section{Case Reports in Oncology}

\begin{tabular}{l|l}
\hline Case Rep Oncol 2017;10:656-659 \\
\hline DOI: 10.1159/000477844 & $\begin{array}{l}\text { (c) 2017 The Author(s). Published by S. Karger AG, Basel } \\
\text { www.karger.com/cro }\end{array}$ \\
\hline
\end{tabular}

Read and Williams: Recurrent Meningioma of the Cervical Spine, Successfully Treated with Liposomal Doxorubicin

used and long treatment interval meant that at $572 \mathrm{mg}$ total, he is still well below his doxorubicin life limit of $440-550 \mathrm{mg} / \mathrm{m}^{2}$. Should his tumor reawaken, we will restart it. Also, liposomal doxorubicin is less cardiotoxic than conventional doxorubicin and it is not clear that the same life limits apply [6]. He encountered minimal toxicity, which is not unusual for liposomal doxorubicin at this dose and schedule, which we also use for sarcoma, breast cancer, and ovarian cancer. The published report describing the use of liposomal doxorubicin for metastatic meningioma was for a patient with high-grade meningioma [5]. Our patient was unusual in that his meningioma, although aggressive, was of a low histologic grade. We have had two other patients with grade 3 meningioma whom we treated with liposomal doxorubicin, one of whom continued to progress and one whose progression seemed to stop for a time before resuming. One could make a case that perhaps the March 2013 MRI interpreted as progression was actually showing postsurgical changes and that actually after his fourth surgery, he was destined to enjoy a long period of gradually subsiding disease. It is possible, but given his history to that point seems unlikely.

\section{Statement of Ethics}

The treatment of the described patient was done as standard of care. It was not considered experimental. The authors have no ethical conflicts to disclose.

\section{Disclosure Statement}

Neither author has any relevant conflicts of interest.

\section{References}

1 Mathiesen T, Lindquist C, Kihlstrom L, et al: Recurrence of cranial base meningiomas. Neurosurgery 1996;39:2-7; discussion 8-9.

-2 Furtner J, Schopf V, Seystahl K, et al: Kinetics of tumor size and peritumoral brain edema before, during, and after systemic therapy in recurrent WHO grade II or III meningioma. Neuro Oncol 2016;18:401407.

-3 Le Rhun E, Taillibert S, Chamberlain MC: Systemic therapy for recurrent meningioma. Expert Rev Neurother 2016;16:889-901.

4 Wen PY, Quant E, Drappatz J, et al: Medical therapies for meningiomas. J Neurooncol 2010;99:365-378

5 Travitzky M, Libson E, Nemirovsky I, et al: Doxil-induced regression of pleuro-pulmonary metastases in a patient with malignant meningioma. Anticancer Drugs 2003;14:247-250.

6 Xing M, Yan F, Yu S, et al: Efficacy and cardiotoxicity of liposomal doxorubicin-based chemotherapy in advanced breast cancer: a meta-analysis of ten randomized controlled trials. PLoS One 2015;10:e0133569. 


\section{Case Reports in Oncology}
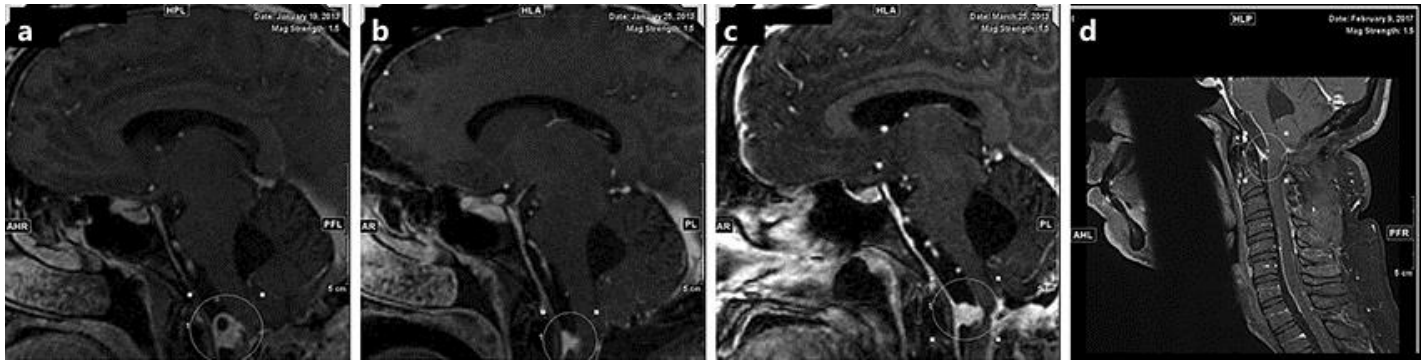

Fig. 1. a MRI of the brain from January 19, 2013 showing enhancing cystic mass at cervicomedullary junction, compressing the spinal cord. b Postoperative MRI of the brain from January 25, 2013 showing decrease in mass but residual enhancing tissue. c Surveillance MRI of the brain from March 25, 2013 showing increase in enhancing mass and increased cord compression. $\mathbf{d}$ Surveillance MRI of the spine from February 9, 2017 showing residual abnormality at the site of the tumor. 